\title{
Homogenous Fluorescent Assays for Characterizing Small-Molecule Activators of AMP-Activated Protein Kinase (AMPK)
}

\author{
Laurie J. Reichling, Steven M. Riddle, Baigen Mei, Rica Bruinsma, Tony A. Goossens, Kristin G. \\ Huwiler, Mark Maffitt, Alyssa M.G. Newport, Xiao-Dong Qian ${ }^{\ddagger}$, Carmen Ruttimann-Johnson, and \\ Kurt W. Vogel*
}

\begin{abstract}
Invitrogen Discovery Sciences, 501 Charmany Dr, Madison, WI 53719 and Invitrogen Corporation, 94/96 South Street, Hopkinton, MA 01748-221, USA
\end{abstract}

\begin{abstract}
AMP activated protein kinase (AMPK) is a key regulator of cellular metabolism. AMPK activity is modulated in part by binding of AMP to the $\gamma$-subunit of the kinase, which increases the activity of the catalytic $\alpha$-subunit. Because increased AMPK activity in the liver and in skeletal muscle leads to increased fatty acid oxidation and decreased cholesterol and fatty acid biosynthesis, activators of AMPK are being sought for treatment of type- 2 diabetes and other metabolic disorders. The unique mechanism of AMPK activation offers an opportunity to develop small molecules that directly upregulate AMPK activity, and there exists a need for simplified methods to identify and characterize small-molecules that show isoform-specific effects on AMPK. We have developed a suite of fluorescence-based assays to identify and characterize such compounds, and have used these to characterize and compare activity of recombinant AMPK $\alpha_{1} \beta_{1} \gamma_{1}$ and $\alpha_{2} \beta_{1} \gamma_{1}$ isoforms in response to small molecule activators and inhibitors.
\end{abstract}

\section{INTRODUCTION}

AMP-activated protein kinase (AMPK) plays a central role in regulating metabolic activity by downregulating ATP-consuming processes and upregulating catabolism in response to environmental stresses that decrease the cellular [ATP]:[AMP] ratio. Upon activation, AMPK phosphorylates and inactivates acetyl CoA carboxylase (ACC, involved in fatty acid biosynthesis), HMG-CoA reductase (a key regulator of cholesterol synthesis and the target of the statin class of drugs) [1], as well as glycogen synthase [2]. AMPK is a heterotrimeric complex consisting of $\alpha, \beta$, and $\gamma$ subunits $[3$, $4]$, and is directly regulated by at least three processes: activation through phosphorylation of Thr-172 in the activation loop of the catalytic $\alpha$ subunit by LKB1 [5-9] or CaMKK $\alpha$ or $\beta[10,11]$, deactivation via dephosphorylation at this site by PP2 [12], and allosteric activation via AMP [13].

AMPK is broadly expressed in a variety of tissues, with different isoforms being dominantly expressed in different tissues. The trimeric complex consists of $\alpha, \beta$, and $\gamma$ subunits, with two isoforms identified for each of the $\alpha$ and $\beta$ subunits, and three identified for the $\gamma$ subunit, giving rise to a possibility of twelve isoforms of AMPK. In liver, the $\alpha_{1}$ and $\alpha_{2}$ subunits are present in approximately equal amounts, with the $\beta_{1}$ and $\gamma_{1}$ being the predominant forms of their respective subunits [14]. In contrast, in heart and in skeletal muscle the $\alpha_{2}$ form predominates over the $\alpha_{1}$ form by a greater than a $2: 1$ ratio, and the $\beta_{2}$ subunit is predominant over the $\beta_{1}$ form in these tissues as well [15].

Therapeutic targeting of AMPK activation has been shown to have positive results in models of diabetes. The small molecule drug metformin has been used for approxi-

*Address correspondence to this author at the Invitrogen Discovery Sciences, 501 Charmany Dr, Madison, WI 53719, USA;

E-mail: kurt.vogel@invitrogen.com mately 50 years in the treatment of type 2 diabetes, and functions by indirectly promoting AMPK phosphorylation and activation [16]. Another small molecule, AICAR (5aminoimidazole-4-carbozamide riboside), has proven to be a useful tool for pharmacologically activating AMPK without perturbing the cellular [ATP]:[AMP] ratio. AICAR is taken up into cells via the adenosine transport system and then phosphorylated to form AICAR monophosphate, or ZMP [17], which activates AMPK by binding to the allosteric AMP-binding site. Recently, the results of a highly miniaturized radiometric assay were reported, in which of a library of over 700,000 compounds was screened for AMPK activators or inhibitors [18], and optimization of hits led to a thienopyridone-based small molecule (A-769662) that activated rat-liver or recombinant AMPK $\left(\alpha_{1} \beta_{1} \gamma_{1}\right)$ with an $\mathrm{EC}_{50}$ of approximately $800 \mathrm{nM}$, and showed positive effects in the treatment of diabetic ob/ob mice [19]. Interestingly, this compound was able to increase AMPK activity in vitro in the presence of saturating amounts of AMP, suggesting the possibility of multiple allosteric sites that can be exploited to develop compounds that activate AMPK. Additionally, AMPK activation has emerged as a therapeutic target for atherosclerosis and cancer [20].

In addition to therapeutic interest in AMPK activation, there is evidence that either direct inhibition [21] or a leptininduced decrease $[22,23]$ in AMPK activity in the hypothalamus can reduce food intake and body weight. Compound $\mathrm{C}$, a pyrazo $[1,5-a]$ pyrimidine compound that inhibits AMPK was discovered in a high-throughput screen [16] and subsequently shown to decrease food intake in mice [21]. Expression of a dominant negative form of AMPK in mouse hypothalamus was shown to reduce both food intake and weight gain, with opposite results seen when a constitutively active form of AMPK was expressed [22].

Because of the key role that AMPK plays in maintaining metabolic homeostasis and the diversity of isoforms that 
exist in different tissues, there is a need for simple, homogenous, non-radiometric methods to identify and characterize small-molecule modulators of AMPK activity. To address this need, we have developed a suite of assays (Fig. 1) for different stages of the discovery process. We have developed a time resolved Förster resonance energy transfer (TRFRET) assay that is well suited to HTS applications, due to its inherent resistance to common forms of assay interference such as colored, fluorescent, or precipitated compounds [24]. Further, we have developed secondary assays that provide a response that is directly proportional to the amount of product formed, and are therefore well suited to detailed mechanistic studies (or hit-confirmation) of small-molecule modulators of AMPK activity. The first of these formats is a FRET-based format in which a peptide substrate for AMPK is labeled on its termini with a coumarin / fluorescein FRET pair. After the kinase reaction, a site-specific protease is added that preferentially cleaves non-phosphorylated substrate, thereby decreasing the FRET signal that remains intact in the non-cleaved, phosphorylated product [25]. In this manner, changes in FRET can be directly correlated to substrate phosphorylation. The second format is based upon the principal of chelate-enhanced fluorescence (CHEF), in which phosphorylation of a serine, threonine, or tyrosine residue causes phosphate-dependent chelation of magnesium between the phosphate group and a non-natural, fluorogenic amino acid (Sox), that has been incorporated into the peptide sequence and that becomes fluorescent upon this chelating event [26]. The FRET-based assay format provides a convenient method for automated compound profiling, and the CHEF-based assay provides the ability to directly monitor purified AMPK activity in real-time.

\section{MATERIALS AND METHODS}

\section{General Reagents}

AMP, ZMP (5-Aminoimidazole-4-carboxamide-1- $\beta$-Dribofuranosyl 5'-monophos-phate), APR (adenosine 5'- monophosphoramidate) and ATMP (adenosine 5'-Othiomonophosphate) were from Sigma-Aldrich (St Louis, MO). Compound C (6-[4-(2-Piperidin-1-yl-ethoxy)phenyl)]-3-pyridin-4-yl-pyrrazolo [1,5-a] - pyrimidine) was from EMD Chemicals Inc (San Diego, CA). TR-FRET based assay reagents (commercialized under the LanthaScreen ${ }^{\mathrm{TM}}$ TR-FRET trade name) and FRET-based assay reagents (commercialized under the Z'-LYTETM trade name) and CAMKK1 were from Invitrogen Discovery Sciences (Madison, WI). CHEF-based assay reagents (commercialized under the Omnia ${ }^{\mathrm{TM}}$ trade name) were from Biosource (Hopkinton, MA). SAMS peptide substrate was from Upstate.

\section{Cloning, Expression, and Purification of AMPK $\alpha_{1} \beta_{1} \gamma_{1}$ and $\alpha_{2} \beta_{1} \gamma_{1}$.}

Genes for the $\alpha_{1}$ (accession \# NP_006242.4), $\alpha_{2}$ (NP_006243.2), and $\beta_{1}$ (NP_006244.2) subunits were fused to the 3' end of the GST gene found in pDEST20 via standard GATEWAY subcloning methods. The $\gamma_{1}$ gene (NP_002724.1) was subcloned in pDEST10 in order to create a vector that would express a protein with an $\mathrm{N}$-terminal His tag. Bacmid DNA was derived from all four vectors, and used to transfect insect cells. AMPK $\alpha_{1} \beta_{1} \gamma_{1}$ and $\alpha_{2} \beta_{1} \gamma_{1}$ were expressed in Sf9 insect cells using an MOI of 1 for each subunit. The cells were harvested 72 hours post infection and the cell paste was stored at $-80^{\circ} \mathrm{C}$ until needed.

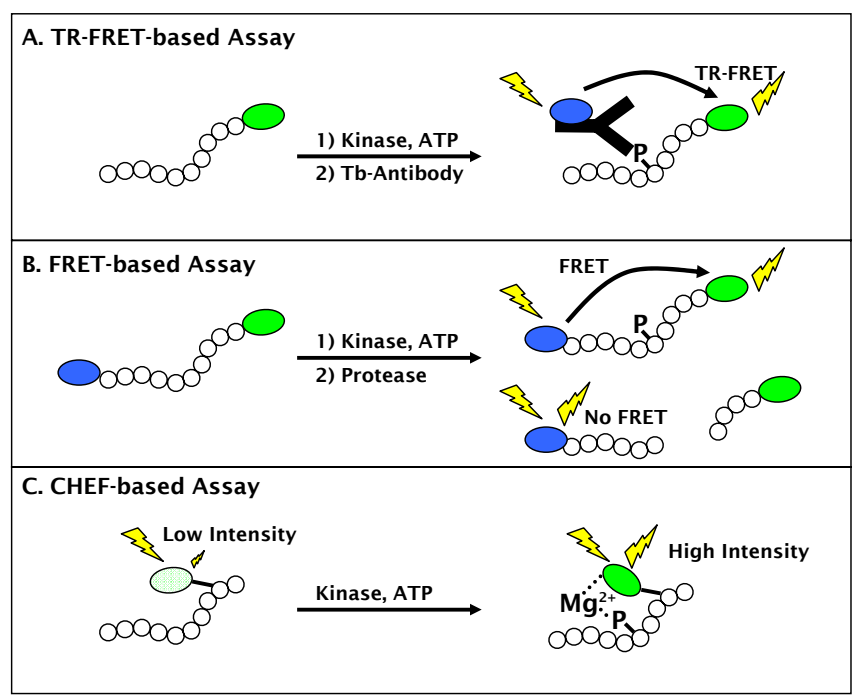

Fig. (1). Schematic of fluorescent assay formats used to characterize AMPK activators of inhibitors. (A) The TR-FRET format detects association between fluorescein labeled, phosphorylated peptide and a terbium-labeled phosphospecific antibody. (B) The FRET-based format uses a peptide substrate terminally labeled with a coumarin-fluorescein FRET pair and measures the amount of phosphorylated product due to a decrease in sensitivity of the phosphorylated peptide to proteolysis. (C) The CHEF-based format uses a peptide substrate that incorporates the non-natural, fluorogenic Sox residue. Upon phosphorylation of a proximal serine, threonine, or tyrosine residue, the Sox moiety forms a $\mathrm{Mg}^{2+}$ mediated bridge between the Sox residue and the phosphate group and becomes fluorescent.

Both AMPK isoforms were purified similarly, and all steps were performed on ice or at $4^{\circ} \mathrm{C}$ unless otherwise stated. Cell paste was suspended in lysis buffer $(20 \mathrm{mM}$ Tris $\mathrm{pH} 8.0,1 \%$ Triton $\mathrm{X}-100,1 \mathrm{mM} \mathrm{Na} \mathrm{VO}_{4}, 25 \mathrm{mM} \beta$ glycerophosphate, $1 \mathrm{mM}$ PMSF, $5 \mathrm{mM}$ benzamidine, 10 $\mu \mathrm{g} / \mathrm{mL}$ leupeptin, $10 \mu \mathrm{M}$ E-64, $2 \mathrm{mM}$ EDTA, and $2 \mathrm{mM}$ DTT), mixed with a hand-held homogenizer, and then clarified by centrifugation. The clarified lysate was then purified on glutathione sepharose $4 \mathrm{~B}$, and fractions containing significant amounts of AMPK as determined by SDS-PAGE were pooled and passed over a Superdex 200 column. Fractions were collected and pooled based on purity as assessed by SDS-PAGE and by activity as analyzed by a radiometric activity assay using SAMS peptide. AMPK was then concentrated to $0.3 \mathrm{mg} / \mathrm{mL}$, and activated by incubation at room temperature for 2 hours with his-tagged CAMKK1 $(0.1 \mathrm{mg}$ per mg of AMPK), $1 \mathrm{mM} \mathrm{ATP,} 10 \mathrm{mM} \mathrm{MgCl} 2,10 \mu \mathrm{g} / \mathrm{mL}$ calmodulin, and $0.5 \mathrm{mM} \mathrm{CaCl}_{2}$, followed by further purification on glutathione sepharose $4 \mathrm{~B}$ to remove CAMKK1. The purified enzyme was dialyzed into storage buffer $(50 \mathrm{mM}$ Tris $\mathrm{pH} 7.5,50 \%$ glycerol, $150 \mathrm{mM} \mathrm{NaCl}, 0.02 \%$ Triton $\mathrm{X}$ $100,0.5 \mathrm{mM}$ EDTA, and $2 \mathrm{mM}$ DTT) and stored at $-80^{\circ} \mathrm{C}$ until use.

\section{Radiometric Assays}

Kinase reactions were performed at room temperature in $50 \mathrm{mM}$ HEPES pH 7.5, 0.01\% BRIJ-35, $10 \mathrm{mM} \mathrm{MgCl}_{2}$, and $1 \mathrm{mM}$ EGTA in a $30 \mu \mathrm{L}$ assay volume in 96-well plates. For 
the inhibition experiments, a 2-fold dilution series of inhibitor stock solutions was first prepared in $100 \%$ DMSO at 100fold concentration of inhibitor to be used in the assay. Prior to the assay, $4 \mu \mathrm{L}$ of each inhibitor concentration was further diluted to $100 \mu \mathrm{L}$ in assay buffer to prepare a working stock of inhibitor in 4\% DMSO at 4-fold the final assay concentration. For the activation experiments, activators were prepared in $100 \% \mathrm{H}_{2} \mathrm{O}$ at 4 -fold the concentration to be tested in the assay. Assays were performed as follows: $7.5 \mu \mathrm{L}$ of the inhibitor or activator working stock was added to a $17.5 \mu \mathrm{L}$ solution of assay buffer, substrate and $\left[{ }^{32} \mathrm{P}\right]$-ATP $(0.5$ $\mu \mathrm{Ci} /$ well), followed by $5 \mu \mathrm{L}$ of enzyme to start the assay. All assays were performed in triplicate. The final concentration of SAMS peptide substrate in the reaction was $200 \mu \mathrm{M}$. AMPK $\alpha_{1} \beta_{1} \gamma_{1}$ was used at $334 \mathrm{ng} / \mathrm{mL}(1.8 \mathrm{nM})$ in the inhibition experiments and $83.3 \mathrm{ng} / \mathrm{mL}(0.44 \mathrm{nM})$ in the activation experiments, at an ATP concentration of $35 \mu \mathrm{M}$. AMPK $\alpha_{2} \beta_{1} \gamma_{1}$ was used at $1670 \mathrm{ng} / \mathrm{mL}(8.9 \mathrm{nM})$ in the inhibition experiments and $267 \mathrm{ng} / \mathrm{mL}(1.4 \mathrm{nM})$ in the activation experiments, at an ATP concentration of $65 \mu \mathrm{M}$. After 10 minutes, $20 \mu \mathrm{L}$ of the reaction was spotted onto a p 81 filter. The filters were washed three times in $0.5 \%$ phosphoric acid, and twice in distilled water before being counted in Beckman Coulter Ready Safe liquid scintillation cocktail using a Beckman Coulter LS6500 Multipurpose Scintillation Counter. Scintillation Counter output (cpm) was used to calculate specific activity (nmole / (min॰mg)).

\section{Time-Resolved FRET (TR-FRET) Activity Assays}

Kinase reactions were performed in a $10 \mu \mathrm{L}$ assay volume at room temperature in 384-well low volume plates (Corning model 3676) using the same assay buffer as the radiometric assay. Activators and inhibitors were prepared as described for the radiometric assay. Assays were performed as follows: $2.5 \mu \mathrm{L}$ of the inhibitor or activator working stock was added to a $5 \mu \mathrm{L}$ solution of kinase and substrate, followed by $2.5 \mu \mathrm{L}$ of ATP to start the assay. Assays were performed in quadruplicate. The final concentration of fluorescein-labeled CREBtide peptide substrate (derived from residues 123-136 of CREB protein) in the reaction was 400 nM. AMPK $\alpha_{1} \beta_{1} \gamma_{1}$ was used at $600 \mathrm{ng} / \mathrm{mL}(3.1 \mathrm{nM})$ in the inhibition experiments and $200 \mathrm{ng} / \mathrm{mL}(1.1 \mathrm{nM})$ in the activation experiments, at an ATP concentration of $50 \mu \mathrm{M}$. AMPK $\alpha_{2} \beta_{1} \gamma_{1}$ was used at $5 \mu \mathrm{g} / \mathrm{mL}(26.5 \mathrm{nM})$ in the inhibition experiments and $600 \mathrm{ng} / \mathrm{mL}(3.2 \mathrm{nM})$ in the activation experiments, at an ATP concentration of $150 \mu \mathrm{M}$. After one hour, a $10 \mu \mathrm{L}$ solution of EDTA and terbium labeled phospho-specific antibody in $20 \mathrm{mM}$ Tris, $\mathrm{pH} 7.5$ and $0.01 \%$ NP40 was added to a final well volume of $20 \mu \mathrm{L}$, a final antibody concentration of $1 \mathrm{nM}$, and a final EDTA concentration of $10 \mathrm{mM}$. After a 30 minute incubation at room temperature the assay plate was read on a BMG Pherastar plate reader using the LanthaScreen ${ }^{\mathrm{TM}}$ filter module. The TR-FRET ratio was calculated as the intensity of the acceptor signal divided by the intensity of the donor signal.

\section{FRET-based Kinase Activity Assays}

Kinase reactions were performed in a $10 \mu \mathrm{L}$ assay volume at room temperature in 384-well low volume plates (Corning model 3676) using the same assay buffer as the radiometric assay. Inhibitors and activators were prepared as described for the radiometric assays. Assays were performed as follows: $2.5 \mu \mathrm{L}$ of the inhibitor or activator working stock was added to a $5 \mu \mathrm{L}$ solution of kinase and substrate, followed by $2.5 \mu \mathrm{L}$ of ATP to start the assay. All assays were performed in quadruplicate. The final concentration of $Z^{\prime}$ $\mathrm{LYTE}^{\mathrm{TM}} \mathrm{S} / \mathrm{T} 23$ peptide substrate in the reaction was $2 \mu \mathrm{M}$. AMPK $\alpha_{1} \beta_{1} \gamma_{1}$ was used at $79 \mathrm{ng} / \mathrm{mL}(0.42 \mathrm{nM})$ in the inhibition experiments and $41 \mathrm{ng} / \mathrm{mL}(0.22 \mathrm{nM})$ in the activation experiments, at an ATP concentration of $50 \mu \mathrm{M}$. AMPK $\alpha_{2} \beta_{1} \gamma_{1}$ was used at $177 \mathrm{ng} / \mathrm{mL}(0.92 \mathrm{nM})$ in the inhibition experiments and $41 \mathrm{ng} / \mathrm{mL}(0.22 \mathrm{nM})$ in the activation experiments, at an ATP concentration of $150 \mu \mathrm{M}$. After one hour, $5 \mu \mathrm{L}$ of protease solution was added to a final well volume of $15 \mu \mathrm{L}$. After a 1 hour incubation at room temperature the assay plate was read on a Tecan Safire plate reader using an excitation wavelength of $400 \mathrm{~nm}$ (12 $\mathrm{nm}$ bandpass), and emission wavelengths of $445 \mathrm{~nm}$ (12 $\mathrm{nm}$ bandpass) and $520 \mathrm{~nm}$ (12 nm bandpass). The FRET ratio was calculated as the intensity of the donor signal divided by the intensity of the acceptor signal. The extent of substrate phosphorylation was calculated from the FRET ratio as described previously [25].

\section{Chelation Enhanced Fluorescence (CHEF)-Based Activ- ity Assays}

Kinase reactions were performed in a $50 \mu \mathrm{L}$ reaction volume at $30^{\circ} \mathrm{C}$ in 96 -well half-area plate (Corning Model 3992) using the same assay buffer as the radiometric assays. Inhibitors and activators were prepared as described for the radiometric assays. Assays were performed by mixing $10 \mu \mathrm{L}$ enzyme solution, $10 \mu \mathrm{L}$ of substrate peptide solution, $10 \mu \mathrm{L}$ of AMP solution (or $\mathrm{H}_{2} \mathrm{O}$ for the activator experiments), and $10 \mu \mathrm{L}$ of inhibitor or activator solution. The reactions were initiated by adding $10 \mu \mathrm{L}$ of ATP solution. The final concentration of Omnia ${ }^{\mathrm{TM}} \mathrm{S} / \mathrm{T} 23$ peptide substrate in the reaction was $8 \mu \mathrm{M}$. AMPK $\alpha_{1} \beta_{1} \gamma_{1}$ was used at $320 \mathrm{ng} / \mathrm{mL}(1.7 \mathrm{nM})$, at an ATP concentration of $40 \mu \mathrm{M}$. AMPK $\alpha_{2} \beta_{1} \gamma_{1}$ was used at $640 \mathrm{ng} / \mathrm{mL}(3.4 \mathrm{nM})$, at an ATP concentration of $120 \mu \mathrm{M}$. The concentration of AMP in the inhibitor titrations was 80 $\mu \mathrm{M}$. Immediately after addition of ATP the assay plate was placed into a fluorescence plate reader (Molecular Devices SpectraMax M5, pre-warmed to $30^{\circ} \mathrm{C}$ ). The plates were read for 60 minutes using an excitation wavelength of $360 \mathrm{~nm}$ and emission wavelength of $485 \mathrm{~nm}$. The reaction rates were calculated as the change in fluorescence intensity over time (Rfu/sec) over the period where the assay response was linear.

\section{Data Analysis}

Data analysis and curve-fitting was performed using GraphPad Prism software (GraphPad Software, Inc, San Diego CA). Curves were fit using a 4-parameter non-linear regression, with the "top" of the curve set to a fixed value such that datapoints prior to a decrease in AMPK activity (due to competition at the ATP site) showed minimal deviation from the calculated curve.

\section{RESULTS AND DISCUSSION}

\section{Expression and Purification of Recombinant Human AMPK $\alpha_{1} \beta_{1} \gamma_{1}$ and $\alpha_{2} \beta_{1} \gamma_{1}$ from Insect Cells}

Structural studies of the heterotrimer have demonstrated that the $\alpha$ and $\beta$ subunits interact with one another via their C-termini [27]. The C-terminus of the $\beta$ subunit also inter- 


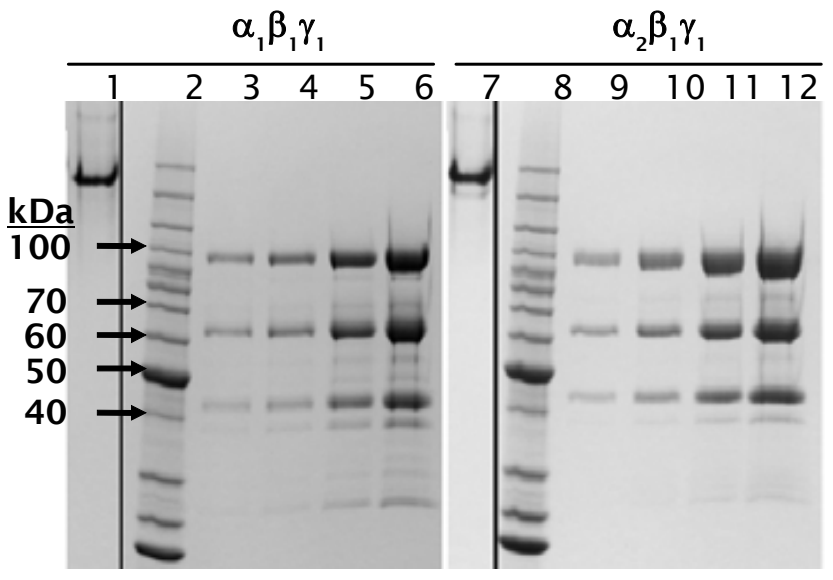

Fig. (2). SDS-PAGE and native gel analysis of AMPK $\alpha_{1} \beta_{1} \gamma_{1}$ and $\alpha_{2} \beta_{1} \gamma_{1}$. Lanes 1 and 7: native (non-denaturing) PAGE samples. Lanes 2 and 8: Invitrogen Benchmark protein ladder. Lanes 3 - 6: AMPK $\alpha_{1} \beta_{1} \gamma_{1}$ loaded at $1,2,5$, or $10 \mu \mathrm{g} /$ lane. Lanes $9-12$ : AMPK $\alpha_{2} \beta_{1} \gamma_{1}$ loaded at $1,2,5$, or $10 \mu \mathrm{g} /$ lane. The GST-tagged $\alpha_{1}$ and $\alpha_{2}$ subunits have calculated molecular weights of 90.8 and $91.4 \mathrm{kDa}$, respectively. The GST-tagged $\beta_{1}$ and 6-His-tagged $\gamma_{1}$ subunits have calculated molecular weights of 57.8 and $41.7 \mathrm{kDa}$, respectively.

acts with the $\gamma$ subunit, but the $\gamma$ subunit contact points are more centrally located [28, 29]. The former observation suggested that attaching large purification tags (e.g. GST) to the $\alpha$ and $\beta$ C-termini could be contraindicated. The latter observation was taken as an indication that a small tag (e.g. 6x His) would be prudent irrespective of the tag location. Indeed, various permutations of tagged subunits were tested, and those discussed here were the only combinations that gave enzymatically active heterotrimeric protein (data not shown).

Both AMPK isoforms could be purified to approximately $80 \%$ purity as assessed by SDS-PAGE by a single purification step on GSH-sepharose, and further purification by sizing column yielded material that was $>85 \%$ pure by SDSPAGE analysis. Purified recombinant AMPK ran as a single distinct band by native PAGE analysis, indicating that all three AMPK subunits expressed in insect cells form a stable heterotrimeric complex (Fig. 2). In contrast to trimeric AMPK expressed in $E$ coli, which showed no detectable activity until activated by an upstream kinase [30], trimeric

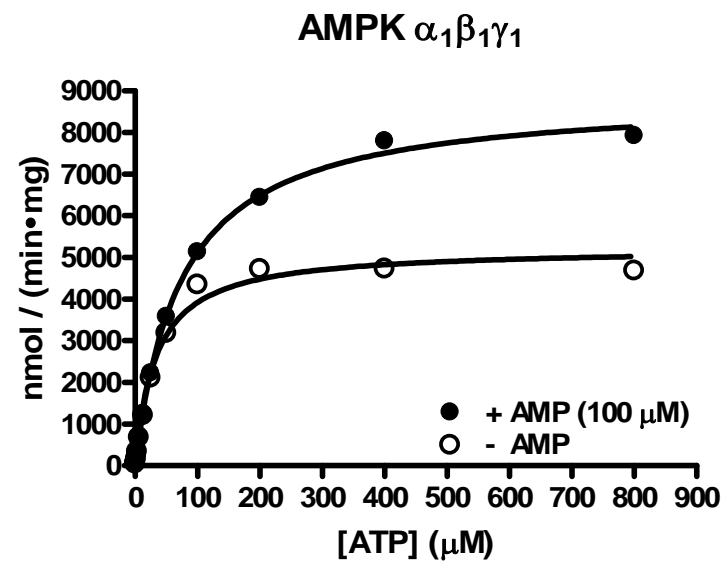

AMPK expressed and purified from insect cells showed measurable activity that could be increased 5- to 6- fold with CAMKK1 (Fig. 3). Both $\alpha_{1} \beta_{1} \gamma_{1}$ and $\alpha_{2} \beta_{1} \gamma_{1}$ isoforms were activated to a similar level of activity using either CAMKK1 or LKB1/STRAD $\alpha / \mathrm{MO} 25 \alpha$ (data not shown).

\section{ATP $K_{m}$ Determination}

ATP $\mathrm{K}_{\mathrm{m}}$ determinations were performed for both AMPK isoforms in the radiometric assay format using saturating concentrations of SAMS substrate in the presence or absence of $100 \mu \mathrm{M}$ AMP (Fig. 4). The $\alpha_{1} \beta_{1} \gamma_{1}$ isoform showed an ATP $\mathrm{K}_{\mathrm{m}}$ of $34 \mu \mathrm{M}$ in the absence of AMP, and $74 \mu \mathrm{M}$ in the presence of AMP (Table 1). The $\alpha_{2} \beta_{1} \gamma_{1}$ isoform showed similar values of $65 \mu \mathrm{M}$ and $73 \mu \mathrm{M}$ in the absence or presence of AMP, respectively. These values are similar to those previously reported for purified rat liver AMPK, which were $86 \mu \mathrm{M}$ or $70 \mu \mathrm{M}$ in the absence or presence of AMP, respectively [31], and were on the order of the apparent ATP $K_{m}$ values determined in the fluorescent assay formats (Table $\mathbf{1}$ ).

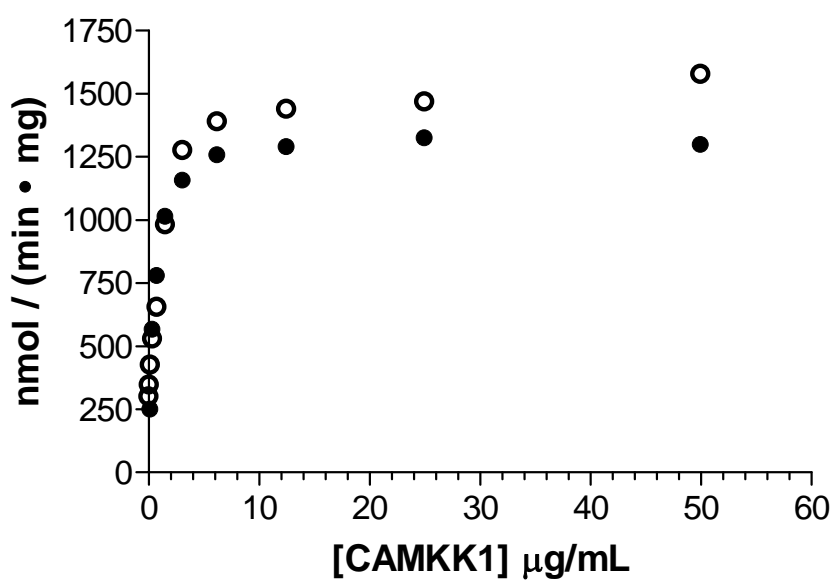

Fig. (3). Activation of AMPK $\alpha_{1} \beta_{1} \gamma_{1}(\bullet)$ and AMPK $\alpha_{2} \beta_{1} \gamma_{1}(\circ)$ by CAMKK1. Activity of AMPK was determined after a 2 hour incubation with CAMKK1 at room temperature.

\section{Comparison of Small-Molecule Modulators on AMPK $\alpha_{1} \beta_{1} \gamma_{1}$ and $\alpha_{2} \beta_{1} \gamma_{1}$ Activity}

Compound $\mathrm{C}$ was originally described as the first "specific" inhibitor of AMPK [16], but has recently been shown to inhibit a range of other kinases $[32,33]$. In our hands, compound $\mathrm{C}$ showed a slight ( $<3$-fold) specificity towards the $\alpha_{2} \beta_{1} \gamma_{1}$ isoform in all assay formats tested (Table $\mathbf{1}$ ), with

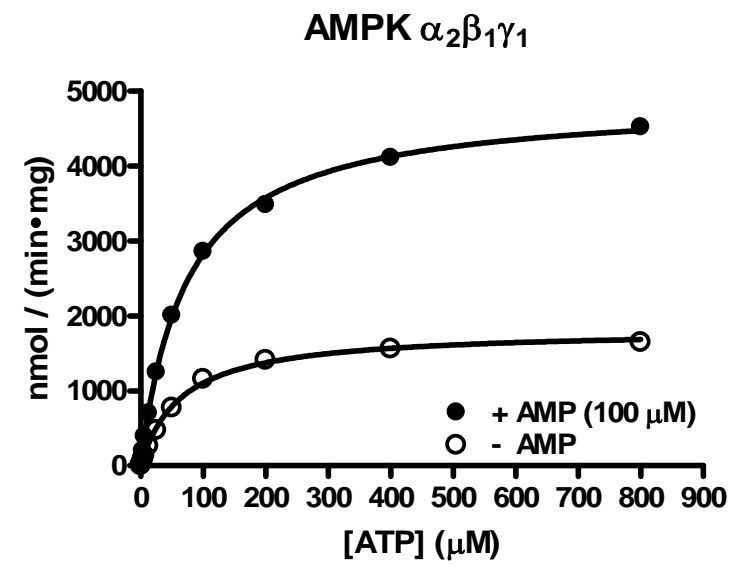

Fig. (4). Radiometric assay of AMPK $\alpha_{1} \beta_{1} \gamma_{1}$ and $\alpha_{2} \beta_{1} \gamma_{1}$ in the presence or absence of AMP. 
Table 1. Summary Comparison of AMPK Isoform Properties. n.d. = Not Determined, n.a. $=$ Not Applicable

\begin{tabular}{|c|c|c|c|c|c|c|c|c|}
\hline \multirow{2}{*}{$\begin{array}{l}\text { AMPK } \\
\text { Isoform }\end{array}$} & \multirow{2}{*}{$\begin{array}{c}\text { Assay } \\
\text { Format }\end{array}$} & \multicolumn{2}{|c|}{$\operatorname{ATP} \mathbf{K m}(\mu \mathrm{M})$} & \multirow{2}{*}{$\begin{array}{c}\text { Inhibitor } \\
\mathbf{I C}_{\mathbf{5 0}}(\mathbf{n M}) \\
C p d C\end{array}$} & & & & \\
\hline & & - AMP & $(100 \mu \mathrm{M})$ & & $A M P$ & $Z M P$ & $A P R$ & ATMP \\
\hline$\alpha_{1} \beta_{1} \gamma_{1}$ & Radiometric & 34 & 74 & 230 & 1.6 / 1.7-fold & $165 / 1.5$-fold & n.d. / n.a. & $0.7 / 1.7$-fold \\
\hline$\alpha_{1} \beta_{1} \gamma_{1}$ & TR-FRET & n.d. & n.d. & 700 & 1.4 / n.a. & $74 /$ n.a. & 722 / n.a. & $0.25 /$ n.a. \\
\hline$\alpha_{1} \beta_{1} \gamma_{1}$ & CHEF & 31 & 25 & 343 & $0.6 / 1.8$-fold & $36 / 1.8$-fold & n.d. / n.a. & $0.25 / 1.8$-fold \\
\hline$\alpha_{2} \beta_{1} \gamma_{1}$ & Radiometric & 65 & 73 & 88 & 1.4 / 2.5 -fold & $54 / 2.5$-fold & 194 / 1.9-fold & 0.13 / 2.9-fold \\
\hline$\alpha_{2} \beta_{1} \gamma_{1}$ & TR-FRET & n.d. & n.d. & 500 & $0.35 /$ n.a. & 23 / n.a. & $43 /$ n.a. & 0.04 / n.a. \\
\hline$\alpha_{2} \beta_{1} \gamma_{1}$ & FRET & 165 & 154 & 140 & 1.4 / 5-fold & 40 / 6.3 -fold & n.d. / n.a. & $0.10 / 6.3$-fold \\
\hline
\end{tabular}

$\mathrm{IC}_{50}$ values on the order of the previously reported $109 \mathrm{nM}$ against rat liver AMPK [16], as well as the slightly higher value shown in other studies [34].

AMPK activation experiments were performed using AMP and a panel of three AMP analogs that were chosen based on previous literature reports. The bulk of the AMP analogs tested caused a compound-dependent increase in AMPK activity that reached a maximal value before causing a decrease in activity (Fig. 5). This decrease in activity is due to competition of the AMP analog for the ATP binding site, such as has been observed by others $[17,35]$. When the activation assays were repeated in the FRET-based assay using higher concentrations of ATP, the point at which activity began to decrease was shifted to higher concentrations of activator, consistent with competition of the AMP analogs for ATP at the ATP binding site (data not shown).

ATMP, a thiophosphate analog of AMP, was the most potent activator tested in all assay formats, with a halfmaximal stimulatory concentration of less than $1 \mu \mathrm{M}$ (Fig. 5 and Table 1). It also began to inhibit AMPK at a concentration lower than that observed for the other AMP analogs, inhibiting kinase activity at concentrations above $10-100$ $\mu \mathrm{M}$ in all formats. When comparing between the two AMPK isoforms, the $\alpha_{2} \beta_{1} \gamma_{1}$ isoform showed half-maximal stimulation at activator concentrations 3 to 6-fold lower than seen for the $\alpha_{1} \beta_{1} \gamma_{1}$ isoform in all assay formats, and comparing between the assay formats for each AMPK isoform, the TRFRET or CHEF-based assay showed the lowest $\mathrm{EC}_{50}$ values, approximately 3 - fold lower than the radiometric assay. In addition to being more sensitive to stimulation by ATMP, the $\alpha_{2} \beta_{1} \gamma_{1}$ isoform also showed an approximately 2-fold greater degree of stimulation than the $\alpha_{1} \beta_{1} \gamma_{1}$ isoform. In the radiometric assay, ATMP stimulated the $\alpha_{1} \beta_{1} \gamma_{1}$ isoform 1.7fold and the $\alpha_{2} \beta_{1} \gamma_{1}$ isoform 2.9-fold, comparable to that seen in the CHEF-based format (1.8- and 2.5-fold for the $\alpha_{1} \beta_{1} \gamma_{1}$ and $\alpha_{2} \beta_{1} \gamma_{1}$ forms, respectively). A greater degree of stimulation for both AMPK isoforms was observed in the FRETbased assay, where ATMP stimulated the $\alpha_{1} \beta_{1} \gamma_{1}$ isoform 3.3fold and the $\alpha_{2} \beta_{1} \gamma_{1}$ isoform 6.3-fold. Overall, these results compare with those previously reported, in which ATMP stimulated partially purified human AMPK 2.5-fold, and partially purified rat AMPK 3-fold, with a half-maximal stimulatory concentration of $0.65 \mu \mathrm{M}$ observed for rat AMPK, which then inhibited activity above $25 \mu \mathrm{M}$ [35].

The physiological activator AMP was the next most potent activator of each AMPK isoform, with half-maximal stimulation occurring at low- to sub- $\mu \mathrm{M}$ concentrations. As with ATMP, there was a slight preference in sensitivity (EC $\mathrm{E}_{50}$ ) towards activation of the $\alpha_{2} \beta_{1} \gamma_{1}$ isoform, ranging from 1.1-fold in the radiometric format to 4-fold in the TRFRET format. Additionally and as with ATMP, the extent to which activity could be increased was greatest for the $\alpha_{2} \beta_{1} \gamma_{1}$ isoform, ranging from 2.5 -fold in the radiometric assay to 5fold in the FRET-based assay. These results are consistent with previous studies comparing activation between the $\alpha_{1} \beta_{1} \gamma_{1}$ and $\alpha_{2} \beta_{1} \gamma_{1}$ complexes in which individual isoforms of rat liver AMPK were immunoprecipitated either from rat liver [36] or from mammalian cells expressing recombinant trimeric rat AMPK [37]. In these previous studies the $\alpha_{1} \beta_{1} \gamma_{1}$ isoform was maximally activated between 1.7- and 3-fold by AMP, whereas $\alpha_{2} \beta_{1} \gamma_{1}$ isoform was maximally activated between 3- and 5.5-fold. However, in these previous studies, the half- maximal concentration of AMP required for activation was 2- to 3- fold lower for the $\alpha_{1} \beta_{1} \gamma_{1}$ isoform when compared to the $\alpha_{2} \beta_{1} \gamma_{1}$ isoform, which is in contrast to our results for the human isoforms in which both isoforms showed nearly identical sensitivity $\left(\mathrm{EC}_{50}\right)$ to AMP in the radiometric format, and 4-fold greater sensitivity towards the $\alpha_{2} \beta_{1} \gamma_{1}$ isoform in the TR-FRET format. Our AMP activation results for the $\alpha_{1} \beta_{1} \gamma_{1}$ isoform are in good agreement with published results using purified recombinant rat $\alpha_{1} \beta_{1} \gamma_{1}$ AMPK, which showed a maximal 3.3-fold activation of AMPK activity, and a half-maximal stimulation at approximately $1.5 \mu \mathrm{M}[30]$.

The general trends for AMPK activation by ZMP mirrored those seen for ATMP and AMP, albeit with a lower potency than seen for those compounds. Potency was reduced over an order of magnitude relative to AMP against either isoform and in all assay formats, but the maximal stimulation of activity was comparable to that seen with ATMP and AMP, also with slightly higher stimulation and lower $\mathrm{EC}_{50}$ values seen for the $\alpha_{2} \beta_{1} \gamma_{1}$ isoform. For either 


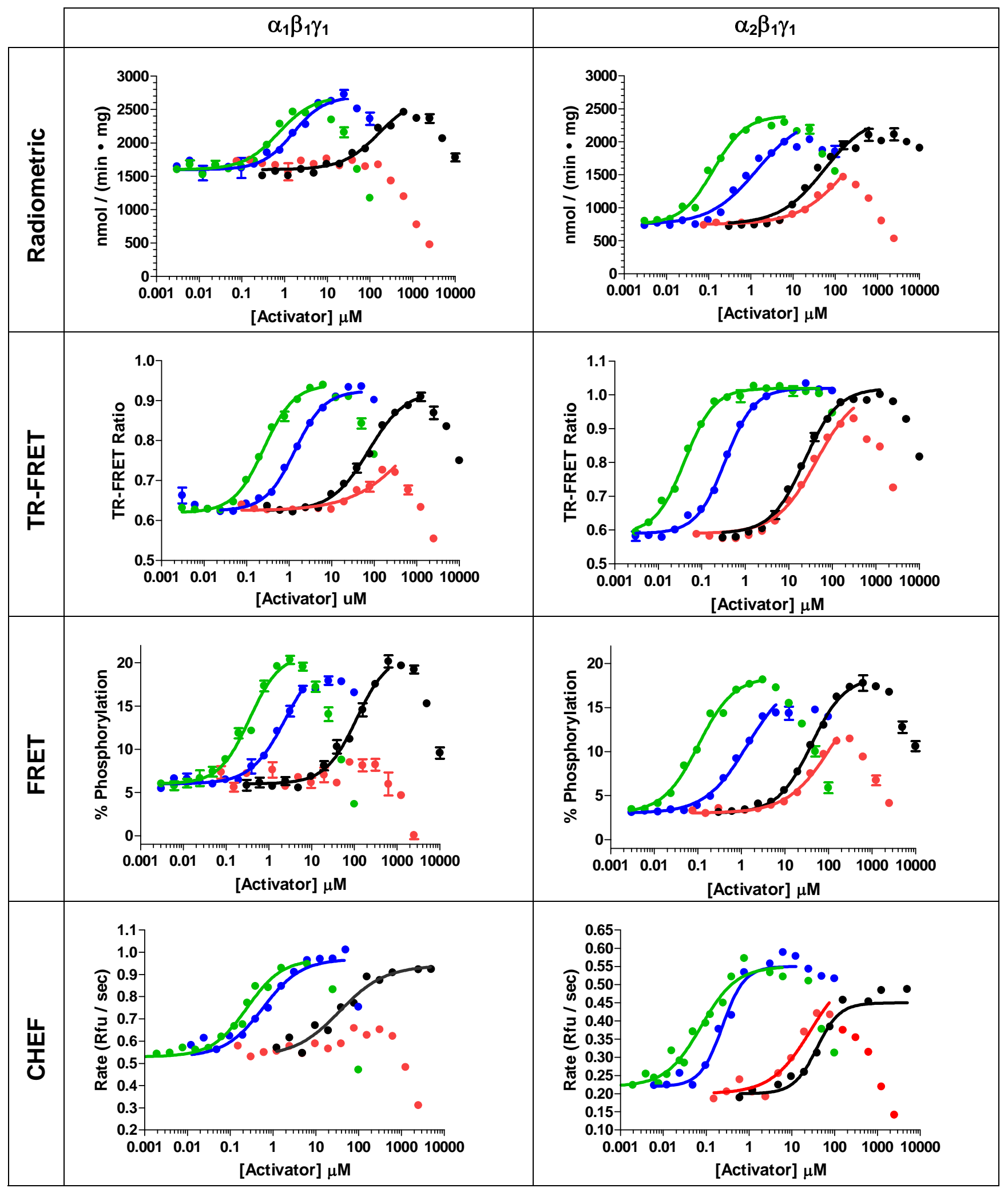

Fig. (5). Small-molecule activation of AMPK $\alpha_{1} \beta_{1} \gamma_{1}$ and $\alpha_{2} \beta_{1} \gamma_{1}$ as determined in different assay formats. AMP (blue circles), ZMP (black circles), ATMP (green circles), APR (red circles).

isoform, the maximum increase in activity was seen in the FRET-based assay format relative to the other formats, with the FRET-based assay showing a maximum impact of ZMP on activity of about twice that seen in the radiometric format for either AMPK isoform. Although we are aware of no studies that compare ZMP activation between different AMPK isoforms, both the magnitude of the increase in activity as well as the half maximal stimulatory concentration observed are consistent with data for rat-liver AMPK, with 
2-3 fold simulation and half-maximal stimulation occurring between 81 and $164 \mu \mathrm{M}$ being reported $[17,35]$.

Finally, the phosphoramidate analog of AMP, APR, was tested as an AMPK activator. The potency of activation was lower than that seen for ZMP in all assay formats except for the CHEF-based format, in which ZMP showed a slightly lower $\mathrm{EC}_{50}$ value for activation. With APR there was a more pronounced overall decrease in kinase activity at higher concentrations than was seen for the other activators. Again, both potency and extent of activation was greater for the $\alpha_{2} \beta_{1} \gamma_{1}$ isoform, with the $\alpha_{1} \beta_{1} \gamma_{1}$ isoform showing negligible activation in any formats before inhibiting kinase activity to below basal levels. The maximal extent of activation for the $\alpha_{2} \beta_{1} \gamma_{1}$ isoform (approximately 2 to 3 fold) is comparable to that reported for partially purified human or rat AMPK (2.25-fold and 1.5-fold, respectively). Although it is difficult to estimate the half-maximal concentration of APR required for stimulation from our data, it appears to be greater than 50 $\mu \mathrm{M}$, which is in contrast to the $1.9 \mu \mathrm{M}$ value reported for rat AMPK [35].

\section{Comparison of Results Between Assay Formats}

For the radiometric, FRET, and CHEF-based assay formats, each assay was performed at an ATP concentration at or near the apparent ATP $K_{m}$ value as determined in that particular format. Because the response of the TR-FRET format is not strictly linear with respect to product formation (rather, it is dependent on the binding of the phosphopeptide product to the antibody), it is difficult to determine a rigorous $\mathrm{K}_{\mathrm{m}}$ value for ATP in this format, and the concentration of ATP used in the assay was chosen to match that of the FRET-based assay.

As a general trend, activator $\mathrm{EC}_{50}$ values were lowest in the CHEF- and TR-FRET formats. The radiometric and CHEF-based assays showed maximal fold-activation values that were comparable to each other, and approximately 2fold lower than in the FRET-based assay (in each case the assays were configured such that at maximal activation less than $30 \%$ of the substrate would be converted to product, insuring that substrate depletion would have minimal impact on the rate of the reaction). Although the fold-activation was not calculated for the TR-FRET assay due to the non-linear relationship between the TR-FRET value and the extent of substrate phosphorylation, the change in the TR-FRET emission ratio was approximately 2 -fold.

The activation data we obtained are consistent with the reported mechanisms for AMP activation of AMPK, in which AMP causes both an increase in the $\mathrm{V}_{\max }$ of the reaction, as well as a decrease in $\mathrm{K}_{\mathrm{m}}$ for the peptide substrate [31, 34, 35]. Additionally, the AMP-dependent changes in both $\mathrm{V}_{\max }$ and $\mathrm{K}_{\mathrm{m}}$ have been shown to differ substantially when different peptide substrates are used. For example, in radiometric studies using 4 similar AMPK substrates it was observed that the AMP-dependent effect on $V_{\text {max }}$ ranged from 2 -fold to more than 8-fold, depending on the particular peptide substrate being used in the assay [34]. Moreover, when peptide substrate $K_{m}$ values were determined in the presence or absence of AMP, a 3-4 fold decrease in peptide $K_{m}$ was observed in the presence of AMP when comparing peptide substrates derived from either ACC or HMG CoA reductase [35]. In our radiometric assay the peptide substrate was used at $200 \mu \mathrm{M}$, which is above its reported $K_{m}$ value, and the $\mathrm{CHEF}$ format used peptide substrate at $8 \mu \mathrm{M}$. In contrast, the substrates used in the FRET- and TR-FRET-based assays were used at much lower concentrations, presumably far below the peptide $\mathrm{K}_{\mathrm{m}}$ value. From the Michaelis-Menten equation:

$$
v=\frac{V_{\max }[S]}{K_{m}+[S]}
$$

it is clear that when [S] $>\mathrm{K}_{\mathrm{m}}$ (as is the case in the radiometric assay), $[\mathrm{S}]$ dominates the denominator, and a decrease in $K_{m}$ for the substrate will have little effect on the rate of the reaction. In contrast, when $[\mathrm{S}]<\mathrm{K}_{\mathrm{m}}$, a decrease in $\mathrm{K}_{\mathrm{m}}$ will have a larger effect on the denominator, and a greater effect on the rate of the reaction. Thus, in assays to identify AMPK activators in which part of the mechanism of activation is a decrease in substrate $K_{m}$, it may be advantageous to format the assay using sub- $\mathrm{K}_{\mathrm{m}}$ concentrations of peptide substrate.

The assay formats used in these studies each offer specific advantages and disadvantages relative to one another, and choice of an assay format should depend on the specific goals of the studies being performed. Although radiometric assays are often criticized due to cost associated with waste disposal and regulatory compliance, they typically offer the widest range of substrate flexibility, both in terms of sequence identity and in the concentration of substrate that can be used in the assay. For example, for rigorous studies of enzyme mechanism it is often desired to use one of the substrates at a concentration above its $\mathrm{K}_{\mathrm{m}}$ value. In a radiometric assay this is limited only by substrate availability (cost) and solubility. In a fluorescence-based assay high concentrations of substrate can be impractical due to inner filter effects (often called "color quenching") caused by the substrate itself, which results in a decrease in assay signal. In a TR-FRET format, additional complications are encountered at high concentration of substrate due to diffusion-enhanced FRET between donor and acceptor fluorophores. In this case, the high concentration of acceptor fluorophore leads to a greater chance of the acceptor diffusing to within a distance from the donor required for efficient FRET during the time that the FRET signal is measured (typically several hundred microseconds). The result is an increase in background signal, and a decrease in assay window. Although fluorescence-based studies may be performed using high concentration of substrate, they often require high dilutions of the reaction prior to measurement which complicates experimental setup and introduces an additional entry point for errors.

An important characteristic of the FRET- and CHEFbased assays is that the assay output is linear with respect to product formation. This is in contrast to the TR-FRET based format, in which assay response is dependant on binding of phosphorylated product to a phosphospecific antibody. This can make the FRET- and CHEF-based formats preferred for mechanistic studies (with the caveats noted above). Additionally, because the CHEF-based format can be monitored in real time, additional information can be readily obtained for so-called "slow binding" inhibitors. Although not shown here, we observed no lag time (within seconds) for AMP activation of AMPK using the CHEF-based assay.

The TR-FRET format is ideally suited to high-throughput screening of large compound libraries. Because the format is 
"time-resolved", optical interference from fluorescent or precipitated compounds (which scatter light) is largely decayed prior to the measurement of the assay signal (in this study, $100 \mu \mathrm{S}$ after excitation). Like the FRET-based format, the ratiometric nature of the measurement also corrects to a large extent for compounds that absorb excitation light, or for minor variations in well-to-well assay volume.

It is interesting to note that all of the AMPK activators tested showed inhibition of activity at high concentration due to competition for ATP at the enzyme active site. As a consequence, when screening large libraries for AMPK modulators, potent activators could be missed when screening at a single compound concentration. Ideally, screens for AMPK activators should be performed at multiple concentrations of compound (i.e. quantitative HTS or "qHTS" format) so that such activity is not overlooked [38].

\section{CONCLUSIONS}

Although detailed studies of AMPK activity against optimized synthetic peptides have been reported [39], AMPK acts on a variety of substrates, both in vitro and in vivo (in the liver alone, at least 9 substrates for AMPK have been identified) [40]. When assaying highly purified recombinant AMPK (in contrast to kinase partially purified from tissues or cells), specificity of the peptide substrate for a single kinase is less of a concern than when assaying kinase isolated from cell or tissue samples, and substrate choice can be made based upon the performance of a particular substrate in a given assay format. In this report, we have demonstrated the ability of a variety of artificial peptide substrates to efficiently serve as substrates for AMPK, and demonstrated that the $\alpha_{2} \beta_{1} \gamma_{1}$ isoform is more sensitive towards AMP and AMP-mimetics than is the $\alpha_{1} \beta_{1} \gamma_{1}$ isoform, and that it can be activated to a greater extent. Additionally, in the course of this work we have developed and described in detail the preparation of recombinant trimeric AMPK from insect cells. Taken together, this work should prove useful in the identification of small molecule probes that will facilitate not only a better understanding of AMPK, but in the development of small molecule therapeutics that target this kinase.

\section{ACKNOWLEDGEMENTS}

The authors thank Leisha Kopp and Dixie Gabel for contributions to the molecular biology and expression stages of this work, Kristin Cleary for assistance with the CHEFbased assays, and Tina Hallis for helpful comments on the manuscript.

\section{REFERENCES}

[1] Carling D, Zammit VA, Hardie DG. A common bicyclic protein kinase cascade inactivates the regulatory enzymes of fatty acid and cholesterol biosynthesis. FEBS Lett 1987; 223(2): 217-22.

[2] Carling D, Hardie DG. The substrate and sequence specificity of the AMP-activated protein kinase. Phosphorylation of glycogen synthase and phosphorylase kinase. Biochim Biophys Acta 1989; 1012(1): 81-6.

[3] Mitchelhill KI, Stapleton D, Gao G, House C, Michell B, Katsis F, et al. Mammalian AMP-activated protein kinase shares structural and functional homology with the catalytic domain of yeast Snf1 protein kinase. J Biol Chem 1994; 269(4): 2361-4.

[4] Davies SP, Hawley SA, Woods A, Carling D, Haystead TA, Hardie DG. Purification of the AMP-activated protein kinase on ATPgamma-sepharose and analysis of its subunit structure. Eur J Biochem 1994; 223(2): 351-7.
[5] Hawley SA, Boudeau J, Reid JL, Mustard KJ, Udd L, Makela TP, et al. Complexes between the LKB1 tumor suppressor, STRAD alpha/beta and MO25 alpha/beta are upstream kinases in the AMPactivated protein kinase cascade. J Biol 2003; 2(4): 28.

[6] Sakamoto K, McCarthy A, Smith D, Green KA, Grahame Hardie $\mathrm{D}$, Ashworth A, et al. Deficiency of LKB1 in skeletal muscle prevents AMPK activation and glucose uptake during contraction. EMBO J 2005; 24(10): 1810-20.

[7] Sakamoto K, Zarrinpashneh E, Budas GR, Pouleur AC, Dutta A Prescott AR, et al. Deficiency of LKB1 in heart prevents ischemiamediated activation of AMPKalpha2 but not AMPKalpha1. Am J Physiol Endocrinol Metab 2006; 290(5): E780-8.

[8] Shaw RJ, Kosmatka M, Bardeesy N, Hurley RL, Witters LA, DePinho RA, et al. The tumor suppressor LKB1 kinase directly activates AMP-activated kinase and regulates apoptosis in response to energy stress. Proc Natl Acad Sci USA 2004; 101(10): 3329-35.

[9] Woods A, Johnstone SR, Dickerson K, Leiper FC, Fryer LG, Neumann $\mathrm{D}$, et al. LKB1 is the upstream kinase in the AMP-activated protein kinase cascade. Curr Biol 2003; 13(22): 2004-8

[10] Hurley RL, Anderson KA, Franzone JM, Kemp BE, Means AR, Witters LA. The $\mathrm{Ca} 2+/$ calmodulin-dependent protein kinase kinases are AMP-activated protein kinase kinases. J Biol Chem 2005; 280(32): 29060-6.

[11] Woods A, Dickerson K, Heath R, Hong SP, Momcilovic M, Johnstone SR, et al. $\mathrm{Ca} 2+/$ calmodulin-dependent protein kinase kinase-beta acts upstream of AMP-activated protein kinase in mammalian cells. Cell Metab 2005; 2(1): 21-33.

[12] Davies SP, Helps NR, Cohen PT, Hardie DG. 5'-AMP inhibits dephosphorylation, as well as promoting phosphorylation, of the AMP-activated protein kinase. Studies using bacterially expressed human protein phosphatase-2C alpha and native bovine protein phosphatase-2AC. FEBS Lett 1995; 377(3): 421-5.

[13] Ferrer A, Caelles C, Massot N, Hegardt FG. Activation of rat liver cytosolic 3-hydroxy-3-methylglutaryl coenzyme A reductase kinase by adenosine 5'-monophosphate. Biochem Biophys Res Commun 1985; 132(2): 497-504.

[14] Cheung PC, Salt IP, Davies SP, Hardie DG, Carling D. Characterization of AMP-activated protein kinase gamma-subunit isoforms and their role in AMP binding. Biochem J 2000; 346 Pt 3: 659-69.

[15] Thornton C, Snowden MA, Carling D. Identification of a novel AMP-activated protein kinase beta subunit isoform that is highly expressed in skeletal muscle. J Biol Chem 1998; 273(20): 1244350 .

[16] Zhou G, Myers R, Li Y, Chen Y, Shen X, Fenyk-Melody J, et al. Role of AMP-activated protein kinase in mechanism of metformin action. J Clin Invest 2001; 108(8): 1167-74.

[17] Corton JM, Gillespie JG, Hawley SA, Hardie DG. 5aminoimidazole-4-carboxamide ribonucleoside. A specific method for activating AMP-activated protein kinase in intact cells? Eur J Biochem 1995; 229(2): 558-65.

[18] Anderson SN, Cool BL, Kifle L, Chiou W, Egan DA, Barrett LW, et al. Microarrayed compound screening (microARCS) to identify activators and inhibitors of AMP-activated protein kinase. J Biomol Screen 2004; 9(2): 112-21.

[19] Cool B, Zinker B, Chiou W, Kifle L, Cao N, Perham M, et al. Identification and characterization of a small molecule AMPK activator that treats key components of type 2 diabetes and the metabolic syndrome. Cell Metab 2006; 3(6): 403-16.

[20] Motoshima H, Goldstein BJ, Igata M, Araki E. AMPK and cell proliferation--AMPK as a therapeutic target for atherosclerosis and cancer. J Physiol 2006; 574(Pt 1): 63-71.

[21] Kim EK, Miller I, Aja S, Landree LE, Pinn M, McFadden J, et al. $\mathrm{C} 75$, a fatty acid synthase inhibitor, reduces food intake via hypothalamic AMP-activated protein kinase. J Biol Chem 2004; 279(19): 19970-6.

[22] Minokoshi Y, Alquier T, Furukawa N, Kim YB, Lee A, Xue B, et al. AMP-kinase regulates food intake by responding to hormonal and nutrient signals in the hypothalamus. Nature 2004; 428(6982): 569-74.

[23] Andersson U, Filipsson K, Abbott CR, Woods A, Smith K, Bloom $\mathrm{SR}$, et al. AMP-activated protein kinase plays a role in the control of food intake. J Biol Chem 2004; 279(13): 12005-8.

[24] Riddle SM, Vedvik KL, Hanson GT, Vogel KW. Time-resolved fluorescence resonance energy transfer kinase assays using physiological protein substrates: applications of terbium-fluorescein and 
terbium-green fluorescent protein fluorescence resonance energy transfer pairs. Anal Biochem 2006; 356(1): 108-16.

[25] Rodems SM, Hamman BD, Lin C, Zhao J, Shah S, Heidary D, et al. A FRET-based assay platform for ultra-high density drug screening of protein kinases and phosphatases. Assay Drug Dev Technol 2002; 1(1 Pt 1): 9-19.

[26] Shults MD, Imperiali B. Versatile fluorescence probes of protein kinase activity. J Am Chem Soc 2003; 125(47): 14248-9.

[27] Iseli TJ, Walter M, van Denderen BJ, Katsis F, Witters LA, Kemp $\mathrm{BE}$, et al. AMP-activated protein kinase beta subunit tethers alpha and gamma subunits via its C-terminal sequence (186-270). J Biol Chem 2005; 280(14): 13395-400.

[28] Viana R, Towler M, Pan DA, Carling D, Viollet B, Hardie DG, et al. A conserved sequence immediately $\mathrm{N}$-terminal to the bateman domains in AMP-activated protein kinase gamma subunits is required for the interaction with the beta subunits. J Biol Chem 2007.

[29] Townley R, Shapiro L. Crystal structures of the adenylate sensor from fission yeast AMP-activated protein kinase. Science 2007; 315(5819): 1726-9.

[30] Neumann D, Woods A, Carling D, Wallimann T, Schlattner U. Mammalian AMP-activated protein kinase: functional, heterotrimeric complexes by co-expression of subunits in Escherichia coli. Protein Expr Purif 2003; 30(2): 230-7.

[31] Carling D, Clarke PR, Zammit VA, Hardie DG. Purification and characterization of the AMP-activated protein kinase. Copurification of acetyl-CoA carboxylase kinase and 3-hydroxy-3methylglutaryl-CoA reductase kinase activities. Eur J Biochem 1989; 186(1-2): 129-36

[32] Hardie DG. AMP-Activated Protein Kinase as a Drug Target. Annu Rev Pharmacol Toxicol 2007; 47: 185-210.
[33] Bain J, Plater L, Elliott M, Shpiro N, Hastie CJ, McLauchlan H, et al. The selectivity of protein kinase inhibitors: a further update. Biochem J 2007; 408(3): 297-315.

[34] Li Y, Cummings RT, Cunningham BR, Chen Y, Zhou G. Homogeneous assays for adenosine 5'-monophosphate-activated protein kinase. Anal Biochem 2003; 321(2): 151-6.

[35] Sullivan JE, Carey F, Carling D, Beri RK. Characterisation of 5'AMP-activated protein kinase in human liver using specific peptide substrates and the effects of 5'-AMP analogues on enzyme activity. Biochem Biophys Res Commun 1994; 200(3): 1551-6.

[36] Salt I, Celler JW, Hawley SA, Prescott A, Woods A, Carling D, et al. AMP-activated protein kinase: greater AMP dependence, and preferential nuclear localization, of complexes containing the alpha2 isoform. Biochem J 1998; 334 (Pt 1): 177-87.

[37] Stein SC, Woods A, Jones NA, Davison MD, Carling D. The regulation of AMP-activated protein kinase by phosphorylation. Biochem J 2000; 345(Pt 3): 437-43.

[38] Inglese J, Auld DS, Jadhav A, Johnson RL, Simeonov A, Yasgar $\mathrm{A}$, et al. Quantitative high-throughput screening: a titration-based approach that efficiently identifies biological activities in large chemical libraries. Proc Natl Acad Sci USA 2006; 103(31): 11473 8.

[39] Dale S, Wilson WA, Edelman AM, Hardie DG. Similar substrate recognition motifs for mammalian AMP-activated protein kinase, higher plant HMG-CoA reductase kinase-A, yeast SNF1, and mammalian calmodulin-dependent protein kinase I. FEBS Lett 1995; 361(2-3): 191-5.

[40] Viollet B, Foretz M, Guigas B, Horman S, Dentin R, Bertrand L, et al. Activation of AMP-activated protein kinase in the liver: a new strategy for the management of metabolic hepatic disorders. J Physiol 2006; 574(Pt 1): 41-53. 